\title{
Soft tissues, areal bone mineral density and hip geometry estimates in active young boys: the PRO-BONE study
}

\author{
Kelly Wilkinson ${ }^{1,2} \cdot$ Dimitris Vlachopoulos $^{1} \cdot$ Panagiota Klentrou $^{3}$. \\ Esther Ubago-Guisado ${ }^{4}$. Augusto César Ferreira De Moraes, ${ }^{5,6,7}$ • Alan R. Barker ${ }^{1}$. \\ Craig A. Williams ${ }^{1} \cdot$ Luis A. Moreno $^{6} \cdot$ Luis Gracia-Marco $^{1,6}$
}

Received: 9 November 2016 / Accepted: 10 February 2017 / Published online: 7 March 2017

(c) The Author(s) 2017. This article is published with open access at Springerlink.com

\begin{abstract}
Purpose Soft tissues, such as fat mass (FM) and lean mass (LM), play an important role in bone development but this is poorly understood in highly active youths. The objective of this study was to determine whether FM or $\mathrm{LM}$ is a stronger predictor of areal bone mineral density (aBMD) and hip geometry estimates in a group of physically active boys after adjusting for height, chronological age, moderate-to-vigorous physical activity (MVPA), FM, and LM.

Methods Participants included 121 boys $(13.1 \pm 1.0$ years $)$ from the PRO-BONE study. Bone mineral content (BMC)
\end{abstract}

Communicated by Olivier Seynnes.

K. Wilkinson and D. Vlachopoulos contributed equally to this work.

Luis Gracia-Marco

L.A.Gracia-Marco@exeter.ac.uk

1 Children's Health and Exercise Research Centre, Sport and Health Sciences, St. Luke's Campus, University of Exeter, Exeter EX1 2LU, UK

2 Peninsula Medical School, Exeter, UK

3 Department of Kinesiology, Brock University, St. Catharines, Ontario, Canada

4 IGOID Research Group, University of Castilla-La Mancha, Toledo, Spain

5 YCARE (Youth/Child cArdiovascular Risk and Environmental) Research Group, University of São Paulo, School of Medicine, São Paulo, São Paulo, Brazil

6 Growth, Exercise, Nutrition and Development Research Group, University of Zaragoza, Zaragoza, Spain

7 Johns Hopkins Bloomberg School of Public Health, Department of Epidemiology, Baltimore, MD, UK and aBMD were measured at total body, femoral neck and lumbar spine using dual-energy X-ray absorptiometry (DXA), and hip structural analysis was used to estimate bone geometry at the femoral neck. Body composition was assessed using DXA. The relationships of FM and LM with bone outcomes were analysed using simple and multiple linear regression analyses.

Results Pearson correlation coefficients showed that total body (less head) aBMD was significantly correlated with LM but not FM. Multiple linear regression analyses showed that FM, after accounting for height, age, MVPA and LM had no significant relationship with aBMD or hip geometry estimates, except for arms aBMD. By contrast, there were positive associations between LM and most aBMD and hip geometry estimates, after accounting height, age, MVPA and FM.

Conclusions The results of this study suggest that LM, and not FM, is the stronger predictor of aBMD and hip geometry estimates in physically active boys.

Trial registration ClinicalTrials.gov ISRCTN17982776.

Keywords Adolescents · Bone health · Hip structural analysis $\cdot$ Body composition $\cdot$ Fat mass $\cdot$ Lean mass

$\begin{array}{ll}\text { Abbreviations } \\ \text { FM } & \text { Fat mass } \\ \text { LM } & \text { Lean mass } \\ \text { aBMD } & \text { Areal bone mineral density } \\ \text { HSA } & \text { Hip structural analysis } \\ \text { DXA } & \text { Dual-energy X-ray absorptiometry } \\ \text { MVPA } & \text { Moderate-to-vigorous physical activity } \\ \text { BMC } & \text { Bone mineral content } \\ \text { QCT } & \text { Quantitative computed tomography }\end{array}$




\section{Introduction}

The pubertal years are recognised as a critical period for bone accrual and for the modification of areal bone mineral density (aBMD) and bone structure (Wang et al. 2009). Bone mass during childhood and adolescence is a key determinant of adult skeletal health (Rizzoli et al. 2010; Gracia-Marco 2016). Accumulating a high peak bone mass during this period may result in suboptimal skeletal development and may predispose to osteoporotic fractures in later life (Joeris et al. 2014). Recent attention has been given to understanding how modifiable soft tissue components, specifically lean mass (LM) and fat mass (FM), are related to bone properties during childhood and adolescence (Jackowski et al. 2014; Edwards et al. 2015). However, there are no previous studies investigating the relationship between LM and FM and bone outcomes in highly active adolescents.

The role of LM in bone development and maintenance is well understood, with mounting evidence suggesting that LM is a major positive contributor to bone mineral content (BMC), aBMD and bone microstructure in non-active children and adolescents (Gracia-Marco et al. 2012; Hoy et al. 2013; El Hage et al. 2009; Farr et al. 2014; Pietrobelli et al. 2002; Hrafnkelsson et al. 2013). The functional model of bone development suggests that the size, structure and strength of bones adapt to dynamic loads associated with muscle contractions rather than to static loads associated with body weight (Scott et al. 2008; Schoenau 2005). Despite consensus regarding the positive association of LM with bone mass (Hrafnkelsson et al. 2013; Jeddi et al. 2015; Mosca et al. 2014; Vlachopoulos et al. 2017), the role of FM in bone development during childhood and adolescence has not been investigated in highly active adolescents. Theoretically, it is plausible that adipose tissue exerts both positive and negative effects on bone via these endocrine pathways (Streeter et al. 2013; Reid 2008). According to the "Functional Muscle-Bone-Unit" the largest physiological loads are caused by muscle contractions, which might be increased in highly active adolescents due to greater muscle forces produced during participation in activities.

The relative contribution of soft tissues to bone outcomes in the non-high active paediatric population is contentious (Cole et al. 2012; Daly et al. 2008). This disagreement may, in part, be explained by inconsistent and often inadequate control of confounding variables, such as physical activity, lean mass and fat mass. Longitudinal data suggests that physical activity exhibit greater increases in LM and bone mass in children and adolescents (Cardadeiro et al. 2014; Lappe et al. 2014). Moreover, mechanical stress on bone during physical activity can interfere with bone loss via adaptations in bone structure and geometry
(Bielemann et al. 2013; Weeks and Beck 2012). However, physically active children and adolescents also have a tendency towards lower FM relative to their total body weight (Lima et al. 2001). Physical activity as an osteoporosis prevention strategy can exert not only direct effects on bone acquisition, but also indirect effects through an associated increase in LM (Bailey et al. 1996; Torres-Costoso et al. 2015).

The majority of research examining the effects of body composition on bone has focussed upon BMC, aBMD, or bone area as its outcomes. However, important differences in bone geometry are not captured during the conventional assessment of BMC, aBMD or bone area (Petit et al. 2005). Based upon a principle first described by Martin and Burr (Beck et al. 1990; Martin and Burr 1984), hip structural analysis (HSA) software derives cross-sectional geometrical and mechanical properties of the proximal femur from dual-energy X-ray absorptiometry (DXA) acquired images, and has been compared favourably with volumetric quantitative computed tomography (QCT) (Prevrhal et al. 2008).

To better understand the relationship between body composition and bone health in highly active adolescents, the present study aimed to examine whether FM or LM is the stronger predictor of aBMD and hip geometry estimates while adjusting for height, chronological age, moderate-tovigorous physical activity (MVPA).

\section{Materials and methods}

\section{Study population}

This study is a cross-sectional analysis of baseline data from 121 male adolescents, obtained between autumn 2014-winter 2015, as part of the on-going longitudinal PRO-BONE study at the Children's Health and Exercise Research Centre, University of Exeter. The PRO-BONE study has been described in detail elsewhere (Vlachopoulos et al. 2015). Briefly, young boys were recruited from schools and sport clubs throughout Southwest England. Data were collected between autumn and winter 2014/15 in one hundred and twenty-one male adolescents: 41 swimmers, 37 footballers, 29 cyclists and 14 non-athletes. The inclusion criteria were: (1) boys $12-14$ years old, engaged ( $\geq 3 \mathrm{~h} /$ week) in osteogenic (football) and/or non-osteogenic (swimming and cycling) sports for the last 3 years or more; (2) boys 12-14 years old not engaged in any of these sports $(\geq 3 \mathrm{~h} /$ week) in the last 3 or more years (non-athletes). Exclusion criteria included: (1) participation in another clinical trial; (2) any acute infection within 1 week of inclusion; (3) history of medical conditions or medications affecting bone metabolism; (4) the presence of an injury prior to inclusion that may affect sport participation or engagement with the 
study; and (5) non-Caucasian individuals. The latter was necessary to avoid differences in body composition (fat, fat-free and bone mass) and biochemical markers between ethnic groups (Bachrach et al. 1999). All parents and participants provided written consent and assent, respectively, and the protocol was approved by: (1) the Ethics Review Sector of Directorate-General of Research (European Commission, ref. number 618496), (2) the Sport and Health Sciences Ethics Committee (University of Exeter, ref. number 2014/766), and (3) the National Research Ethics Service Committee (NRES Committee South West-Cornwall \& Plymouth, ref. number 14/SW/0060).

\section{Anthropometry and maturity}

Standing height $(\mathrm{cm})$ was measured barefoot using a stadiometer (Harpenden, Holtain Ltd, Crymych, UK; precision $0.1 \mathrm{~cm}$; range $60-210 \mathrm{~cm}$ ). Body mass $(\mathrm{kg})$ was measured with participants barefoot and in light indoor clothing using mean from two devices: an electronic scale (Seca 877, Seca Ltd, Birmingham, UK; precision $0.1 \mathrm{~kg}$; range $2-200 \mathrm{~kg}$ ) and a portable bioelectrical impedance analysis device (Tanita BF-350, Tokyo, Japan; range 2-200 kg; precision $100 \mathrm{~g}$ ). Body mass index (BMI, $\mathrm{kg} / \mathrm{m}^{2}$ ) was calculated as body mass divided by height squared.

Pubertal maturation was self-assessed using adapted drawings of the five stages of pubic hair development (Morris and Udry 1980). The five stages were explained to the participants and the validity and reliability of this method has been established previously (Duke et al. 1980).

\section{Body composition}

\section{Dual-energy X-ray absorptiometry (DXA)}

All participants were scanned in the supine position using a single DXA scanner (GE Lunar Prodigy Healthcare Corp., Madison, WI, USA). The device was calibrated each day using a lumbar spine phantom. Four scans were performed to obtain aBMD $\left(\mathrm{g} / \mathrm{cm}^{2}\right)$, and BMC ( $\mathrm{g}$ ) for the lumbar spine (LS, L1-L4), femoral neck of right and left hip, and the total body scan. The total body scan was then used to obtain data for fat mass $(\mathrm{g})$, lean mass $(\mathrm{g})$ and region specific data, including total body less head (TBLH), arms and legs. TBLH values were used in preference to total body for all analyses, and mean values of the right and left sides of the body were used where relevant. Analyses were performed using GE encore software (2006, version 14.10.022). A single trained researcher performed and analysed all DXA scans to standardise the analyses. Participants asked to remain still and scanned in the supine position. The positioning of the participants and the analyses of the results were undertaken according to International
Society of Clinical Densitometry (Crabtree et al. 2014). Previous studies performed in paediatric populations have shown that the DXA percentage coefficient of variation was between 1.0 and $2.9 \%$ depending on the region (Johnson and Dawson-Hughes 1991).

\section{Hip structural analysis (HSA)}

HSA was performed at the narrow neck region across the narrowest point of the femoral neck and the following parameters were obtained: (1) hip section modulus $\left(\mathrm{mm}^{3}\right)$ - an indicator of bending strength for maximum bending stress in the direction of the image plane; (2) cross sectional moment of inertia $\left(\mathrm{mm}^{4}\right)$-an index of structural rigidity; (3) cross sectional area $\left(\mathrm{mm}^{2}\right)$-bone surface area in the cross-section after excluding soft tissue and trabecular space, provides an index of axial compression strength; and (4) diameter of femoral neck ( $\mathrm{mm}$ ). The short-term precision percentage coefficient of variation of these variables has been reported to be between 2.4 and $10.1 \%$ (Khoo et al. 2005).

\section{Physical activity and dietary assessment}

Objective measures of PA were collated using wrist accelerometers (GENEActiv, GENEA, UK) worn on the nondominant wrist with data collected for seven consecutive days. To establish time spent in different exercise intensities, 1-second epoch intervals were used. Time spend in MVPA was calculated using a cut-off point of $\geq 1140$ counts per minute (Phillips et al. 2013; Rich et al. 2013). The MVPA has been calculated as a mean of the days that had at least $10 \mathrm{~h} /$ day and 3 valid days of week including one weekend day. These criteria comply with high reliability $(r=0.86)$ as previously shown the following the recommendation of the accelerometer (GENEA) used (Phillips et al. 2013) and previous studies (Torres-Costoso et al. 2015; Janz et al. 2014).

CompEat Pro software (Nutrition systems, VIS Visual Information Systems Ltd., UK) was used to estimate intake of calcium following self-reported recall of dietary intake from the preceding $24 \mathrm{~h}$. The validity and reliability of selfreported dietary intake has been previously established in children (Weber et al. 2004).

\section{Statistical analyses}

Descriptive data are presented as mean \pm standard deviation. To identify associations between bone parameters and potential regression covariates, bivariate correlations were computed using Pearson product-moment correlation coefficients and Spearman correlation for the categorical variables. Multiple linear regression analyses 
were used to assess the relationships of FM with both aBMD and hip geometry estimates. aBMD was further split into regional analysis of TBLH, total hip, LS (L1-L4), femoral neck, arms and legs. Regression models were built in three steps. In Model 1, height and age were included as covariates. In this study, chronological age demonstrated a stronger correlation with most bone variables than Tanner stage and was, therefore, selected for entry into the model. Model 2 included model $1+$ MVPA to determine its role within this association. Finally, model 3 included model $2+\mathrm{LM}$ to ascertain whether LM had an independent effect on bone outcomes. This method was repeated to examine the associations of LM with aBMD and hip geometry estimates as above, but with adjustment for FM instead of LM in model 3. In addition, all regression models included a treatment dummy variable (football, swimming, cycling, non-athletes) in which non-athletes were the reference group. Independence of residuals was verified using the DurbinWatson statistic and linearity, normality and homoscedasticity assumptions were assessed through visual inspection of residual plots. Signs of multicollinearity between independent variables in the model were assessed using the variance inflation factor (criteria $=\mathrm{VIF} \geq 10$ ).

All analyses were performed using the Statistical Package for Social Sciences software (SPSS, version 22.0, Chicago, IL, USA). An alpha level of 0.05 was considered statistically significant.

Table 1 Descriptive characteristics of young boys $(n=121)$ participating in the PRO-BONE study

\begin{tabular}{|c|c|c|c|c|c|}
\hline Parameters & All $(n=121)$ & Swimmers $(n=41)$ & Footballers $(n=37)$ & Cyclists $(n=29)$ & Controls $(n=14)$ \\
\hline Age (years) & $13.1(1.0)$ & $13.4(1.0)^{\mathrm{b}, \mathrm{d}}$ & $12.8(0.9)$ & $13.2(1.0)^{\mathrm{d}}$ & $12.3(0.5)$ \\
\hline Pubertal maturation (I/II/III/IV/V) (\%) & $19 / 28 / 21 / 30 / 2$ & $16 / 25 / 16 / 43 / 0$ & $24 / 35 / 25 / 16 / 0$ & $14 / 29 / 25 / 28 / 4$ & $29 / 21 / 21 / 29 / 0$ \\
\hline Height $(\mathrm{cm})$ & $159.9(10.6)$ & $165.5(9.7)^{\mathrm{b}, \mathrm{d}}$ & $155.2(9.3)$ & $160.8(9.9)$ & $154.5(9.9)$ \\
\hline Body mass (kg) & $48.6(10.4)$ & $52.4(9.0)^{\mathrm{bb}}$ & $44.3(7.9)$ & $49.5(12.3)$ & $48.3(13.0)$ \\
\hline BMI $\left(\mathrm{kg} / \mathrm{m}^{2}\right)$ & $18.9(2.3)$ & $19.0(1.7)$ & $18.3(1.4)$ & $18.9(3.3)$ & $20.0(3.4)$ \\
\hline Fat mass TBLH (DXA), (kg) & $8.1(5.3)$ & $8.3(3.2)$ & $6.6(2.4)$ & $8.6(7.2)$ & $14.1(8.5)^{\mathrm{a}, \mathrm{b}, \mathrm{c}}$ \\
\hline Lean mass TBLH (DXA), (kg) & $34.3(8.1)$ & $41.6(9.1)^{\mathrm{b}, \mathrm{d}}$ & $35.4(7.2)$ & $37.7(7.5)$ & $31.7(5.5)$ \\
\hline MVPA (min/day) & $101.3(33.8)$ & $85.9(30.4)$ & $119.8(29.7)^{\mathrm{a}, \mathrm{d}}$ & $107.2(33.3)^{\mathrm{a}}$ & $83.2(26.8)$ \\
\hline Calcium intake (mg/day) & $991.59(490.77)$ & $979.5(438.5)$ & $1017.9(504.5)$ & $957.7(526.8)$ & $881.5(380.7)$ \\
\hline \multicolumn{6}{|l|}{ Areal bone mineral density $\left(\mathrm{g} / \mathrm{cm}^{2}\right)$} \\
\hline Total body less head & $0.91(0.08)$ & $0.918(0.067)^{\mathrm{d}}$ & $0.931(0.071)^{\mathrm{d}}$ & $0.905(0.086)^{\mathrm{d}}$ & $0.828(0.071)$ \\
\hline Total hip & $0.97(0.12)$ & $0.962(0.107)^{\mathrm{d}}$ & $1.034(0.085)^{\mathrm{a}, \mathrm{c}, \mathrm{d}}$ & $0.959(0.116)^{\mathrm{d}}$ & $0.830(0.116)$ \\
\hline Lumbar spine, L1-L4 & $0.87(0.11)$ & $0.892(0.114)^{\mathrm{d}}$ & $0.883(0.095)$ & $0.867(0.122)$ & $0.791(0.101)$ \\
\hline Femoral neck & $0.95(0.11)$ & $0.948(0.098)^{\mathrm{d}}$ & $1.001(0.081)^{\mathrm{dd}}$ & $0.975(0.192)^{\mathrm{d}}$ & $0.832(0.118)$ \\
\hline Arms & $0.75(0.07)$ & $0.784(0.071)^{\mathrm{b}, \mathrm{d}}$ & $0.736(0.047)$ & $0.747(0.069)^{\mathrm{d}}$ & $0.690(0.049)$ \\
\hline Legs & $1.08(0.11)$ & $1.091(0.010)$ & $1.124(0.106)$ & $1.077(0.116)$ & $0.975(0.103)$ \\
\hline \multicolumn{6}{|l|}{ Bone mineral content $(\mathrm{g})$} \\
\hline Total body less head & $1505.02(359.78)$ & $1622.75(325.44)^{\mathrm{d}}$ & $1473.49(338.6)$ & $1478.97(353.2)$ & $1234.38(347.86)$ \\
\hline Total hip & $27.64(6.26)$ & $28.79(5.56)^{\mathrm{d}}$ & $28.78(6.18)^{\mathrm{d}}$ & $27.31(5.92)^{\mathrm{d}}$ & $21.12(5.55)$ \\
\hline Lumbar spine, L1-L4 & $39.68(10.63)$ & $42.97(11.37)^{\mathrm{d}}$ & $38.54(8.93)$ & $38.91(10.78)$ & $32.64(8.67)$ \\
\hline Femoral neck & $4.36(0.78)$ & $4.46(0.66)^{\mathrm{d}}$ & $4.53(0.74)^{\mathrm{d}}$ & $4.35(0.76)^{\mathrm{d}}$ & $3.52(0.73)$ \\
\hline Arms & $209.64(63.23)$ & $243.39(64.01)^{\mathrm{b}, \mathrm{d}}$ & $188.34(48.05)$ & $210.62(59.05)^{\mathrm{d}}$ & $155.89(40.58)$ \\
\hline Legs & $742.14 \pm 171.22$ & $775.78(136.24)^{d}$ & $747.84(175.02)$ & $733.99(171.45)$ & $612.28(179.47)$ \\
\hline \multicolumn{6}{|l|}{ Hip structural analysis } \\
\hline Hip section modulus $\left(\mathrm{mm}^{3}\right)$ & $530.93(126.51)$ & $558.3(121.4)^{\mathrm{d}}$ & $548.1(116.7)^{\mathrm{d}}$ & $530.8(123.3)^{\mathrm{d}}$ & $395.0(123.4)$ \\
\hline Cross sectional moment of inertia $\left(\mathrm{mm}^{4}\right)$ & $8331.52(2643.78)$ & $8943.5(2573.6)^{\mathrm{d}}$ & $8471.6(2606.6)^{\mathrm{d}}$ & $8403.1(2552.4)^{\mathrm{d}}$ & $6020.7(2673.0)$ \\
\hline Cross sectional area $\left(\mathrm{mm}^{2}\right)$ & $134.85(22.71)$ & $137.2(20.2)^{\mathrm{d}}$ & $140.9(20.4)^{\mathrm{d}}$ & $135.9(22.7)^{\mathrm{d}}$ & $109.8(21.0)$ \\
\hline Diameter of femoral neck (mm) & $30.6(2.81)$ & $31.2(2.6)^{\mathrm{d}}$ & $30.5(2.8)$ & $30.7(2.6)$ & $28.4(2.5)$ \\
\hline
\end{tabular}

Data presented as mean (standard deviation). Superscript letters denote a higher significant difference with: a (swimmers), b (footballers), c (cyclists), d (controls)

$B M I$ body mass index, $T B L H$ total body less head, $M V P A$ moderate-to-vigorous physical activity

a,b,c,d $p<0.05$ 


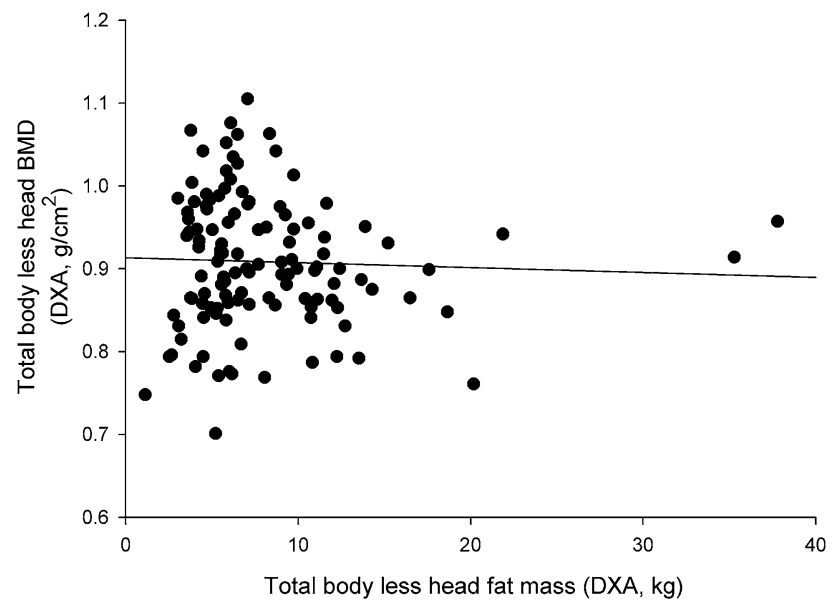

Fig. 1 Association between fat mass (DXA, kg) and areal bone mineral density (DXA, $\mathrm{g} / \mathrm{cm}^{2}$ ) in young boys. Pearson product-moment correlation coefficient, $r=-0.040, p=0.664$

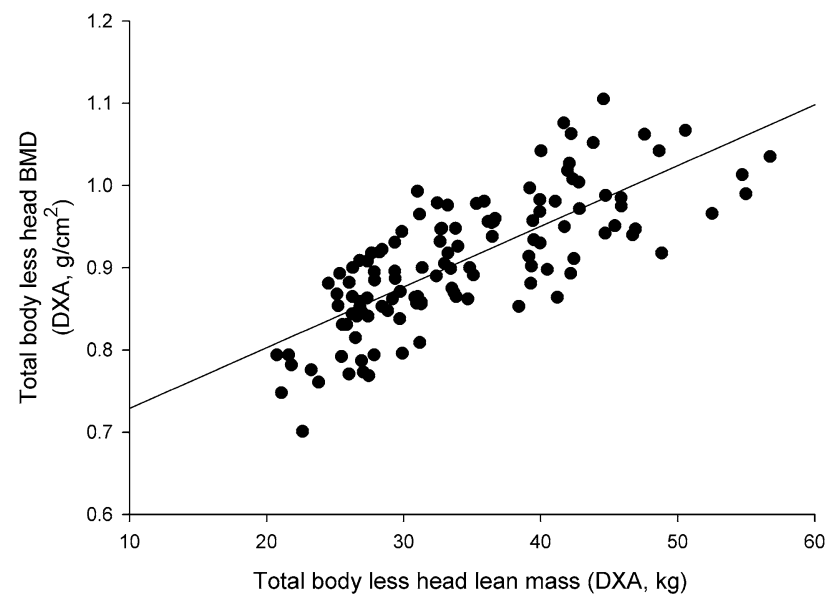

Fig. 2 Association between lean mass (DXA, kg) and areal bone mineral density (DXA, $\mathrm{g} / \mathrm{cm}^{2}$ ) in young boys. Pearson productmoment correlation coefficient, $r=0.761, p<0.001$

\section{Results}

Participant characteristics are summarised in Table 1. The mean age of participants was $13.1 \pm 1.0$ years. Most participants $(91.6 \%)$ exceeded the current recommendation for children and adolescents to accumulate at least $60 \mathrm{~min}$ of MVPA per day.

Age, pubertal stage, height and weight were each positively correlated with aBMD at all sites, as well as with all hip geometry estimates $(p<0.001)$. MVPA was negatively associated $(p<0.01)$ with aBMD of the arms only. Calcium intake was associated with any measure of aBMD or hip geometry estimates (data not shown). Figures 1 and 2 show the associations of total body (less head) aBMD with FM and LM, respectively. aBMD was not significantly correlated with FM ( $r=-0.040 ; p=0.664)$, however, it was positively correlated to $\mathrm{LM}(r=0.761 ; p<0.001)$.

Table 2 shows the results of the regression analysis between FM and bone outcomes after adjusting for potential confounders. After adjusting for height and age in model 1, FM was only negatively associated with aBMD of the LS explaining $14 \%$ of the variance. The significant negative association between FM and aBMD of the LS remained unchanged after MVPA was added into the model 2. Finally, the inclusion of LM as a covariate in model 3 rendered the association of FM with LS aBMD as not significant. However, a positive association for FM with arms aBMD was observed ( $\beta$ changes from 0.043 to 0.113 ).

Regarding the hip geometry estimates, in model $1 \mathrm{FM}$ had a negative association with hip section modulus and cross sectional moment of inertia, explaining 10 and $12 \%$ of the variance respectively. After adjusting for MVPA in model 2, the negative association of FM with cross sectional moment of inertia was marginally attenuated but remained significant, whereas the association with the hip section modulus was not significant. Finally, with the addition of LM in model 3, the significant association between FM and cross sectional moment of inertia was lost.

Table 3 shows the results of the regression analysis between DXA measured LM and bone outcomes after adjusting for potential confounders. In model 1, after adjusting for height and age, LM had a significant positive association with aBMD at all sites except in the femoral neck, explaining between 9 and $37 \%$ of the variance. Adjustment for MVPA in model 2 and FM in model 3 did not significantly change the positive associations between LM and aBMD outcomes. Similar outcomes were also observed for LM and all hip geometry estimates in models 1,2 , and 3 .

The above regression analyses were repeated using BMC regional analyses leading to similar results (data not shown).

\section{Discussion}

Using multiple linear regression analysis, this study found $\mathrm{LM}$, and not FM, to be the strongest predictor of aBMD and hip geometry estimates in a group of physically active boys even after adjusting for various confounding variables. Our findings, therefore, support previous reports that LM has a strong positive relationship with bone outcomes (Gracia-Marco et al. 2012; Hoy et al. 2013; El Hage et al. 2009; Farr et al. 2014), explaining as much as $38 \%$ of the variance in aBMD independently of FM. Conversely, FM was found to be negatively associated with a few parameters related to the structure and strength of bone, and once LM was accounted for, the relationship between FM and 
Table 2 Multiple linear regression analysis of areal bone mineral density (aBMD) and hip structural analysis in young boys $(n=121)$ participating in the PRO-BONE study with regard to DXA derived fat mass

\begin{tabular}{|c|c|c|c|c|c|c|c|c|c|}
\hline \multirow[t]{3}{*}{ Dependent variables } & \multicolumn{9}{|c|}{ FAT MASS (DXA) } \\
\hline & \multicolumn{3}{|c|}{ Model $1^{\mathrm{a}}$} & \multicolumn{3}{|c|}{ Model $2^{\mathrm{b}}$} & \multicolumn{3}{|c|}{ Model $3^{c}$} \\
\hline & $\beta$ & Semip corr & $p$ value & $\beta$ & Semip corr & $p$ value & $\beta$ & Semip corr & $p$ value \\
\hline \multicolumn{10}{|l|}{$\operatorname{aBMD}\left(\mathrm{g} / \mathrm{cm}^{2}\right)$} \\
\hline Total body less head & 0.018 & 0.016 & 0.781 & 0.016 & 0.014 & 0.804 & 0.083 & 0.072 & 0.158 \\
\hline Total hip & -0.089 & -0.078 & 0.255 & -0.087 & -0.077 & 0.246 & -0.058 & -0.050 & 0.463 \\
\hline L1-L4 & -0.158 & -0.140 & 0.050 & -0.160 & -0.141 & 0.049 & -0.090 & -0.078 & 0.230 \\
\hline Femoral neck & -0.052 & -0.046 & 0.518 & -0.050 & -0.044 & 0.534 & -0.030 & -0.026 & 0.716 \\
\hline Arms & 0.054 & 0.047 & 0.468 & 0.049 & 0.043 & 0.507 & 0.134 & 0.116 & 0.034 \\
\hline Legs & 0.035 & 0.031 & 0.586 & 0.033 & 0.029 & 0.613 & 0.096 & 0.084 & 0.103 \\
\hline \multicolumn{10}{|l|}{ Hip structural analysis } \\
\hline Hip section modulus $\left(\mathrm{mm}^{3}\right)$ & -0.118 & -0.104 & 0.049 & -0.110 & -0.097 & 0.062 & -0.055 & -0.047 & 0.308 \\
\hline Cross sectional moment of inertia $\left(\mathrm{mm}^{4}\right)$ & -0.135 & -0.120 & 0.028 & -0.127 & -0.112 & 0.036 & -0.062 & -0.054 & 0.238 \\
\hline Cross sectional area $\left(\mathrm{mm}^{2}\right)$ & -0.099 & -0.088 & 0.120 & -0.094 & -0.083 & 0.140 & -0.044 & -0.038 & 0.463 \\
\hline Diameter of femoral neck (mm) & -0.094 & -0.083 & 0.190 & -0.086 & -0.076 & 0.225 & -0.018 & -0.016 & 0.778 \\
\hline
\end{tabular}

Significant results are in bold $(p$ value $<0.05$ ). All models included a treatment dummy variable (group: football, swimming, cycling and control)

$\beta$ standardised regression coefficient, Semip corr semi-partial (part) correlation, $a B M D$ areal bone mineral density

${ }^{a}$ Model 1 In additional to DXA derived fat mass (total body less head, kilograms), the following independent variables were entered into the model: height (centimeters) and age (years)

${ }^{\mathrm{b}}$ Model 2 model $1+$ moderate-to-vigorous physical activity (minutes per day)

${ }^{\mathrm{c}}$ Model 3 model $2+$ DXA derived lean mass (total body less head, kilograms)

Table 3 Multiple linear regression analysis of areal bone mineral density (aBMD) and hip structural analysis in young boys $(n=121)$ participating in the PRO-BONE study with regard to DXA derived lean mass

\begin{tabular}{|c|c|c|c|c|c|c|c|c|c|}
\hline \multirow[t]{3}{*}{ Dependent variables } & \multicolumn{6}{|c|}{ LEAN MASS (DXA) } & & & \\
\hline & \multicolumn{3}{|c|}{ Model $1^{\mathrm{a}}$} & \multicolumn{3}{|c|}{ Model $2^{\mathrm{b}}$} & \multicolumn{3}{|c|}{ Model $3^{\mathrm{c}}$} \\
\hline & $\beta$ & Semip corr & $p$ value & $\beta$ & Semip corr & $p$ value & $\beta$ & Semip corr & $p$ value \\
\hline \multicolumn{10}{|l|}{$\operatorname{aBMD}\left(\mathrm{g} / \mathrm{cm}^{2}\right)$} \\
\hline Total body less head & 0.734 & 0.292 & $<\mathbf{0 . 0 0 1}$ & 0.734 & 0.291 & $<0.001$ & 0.770 & 0.299 & $<0.001$ \\
\hline Total hip & 0.358 & 0.143 & $\mathbf{0 . 0 3 7}$ & 0.367 & 0.145 & 0.034 & 0.342 & 0.133 & 0.053 \\
\hline L1-L4 & 0.837 & 0.333 & $<0.001$ & 0.840 & 0.333 & $<0.001$ & 0.801 & 0.311 & $<\mathbf{0 . 0 0 1}$ \\
\hline Femoral neck & 0.237 & 0.094 & 0.182 & 0.245 & 0.097 & 0.169 & 0.233 & 0.090 & 0.203 \\
\hline Arms & 0.930 & 0.370 & $<0.001$ & 0.921 & 0.365 & $<0.001$ & 0.980 & 0.381 & $<\mathbf{0 . 0 0 1}$ \\
\hline Legs & 0.690 & 0.275 & $<0.001$ & 0.688 & 0.273 & $<0.001$ & 0.730 & 0.284 & $<0.001$ \\
\hline \multicolumn{10}{|l|}{ Hip structural analysis } \\
\hline Hip section modulus $\left(\mathrm{mm}^{3}\right)$ & 0.627 & 0.250 & $<0.001$ & 0.663 & 0.263 & $<0.001$ & 0.639 & 0.248 & $<0.001$ \\
\hline Cross sectional moment of inertia $\left(\mathrm{mm}^{4}\right)$ & 0.740 & 0.295 & $<0.001$ & 0.777 & 0.308 & $<0.001$ & 0.750 & 0.292 & $<0.001$ \\
\hline Cross sectional area $\left(\mathrm{mm}^{2}\right)$ & 0.563 & 0.224 & $<\mathbf{0 . 0 0 1}$ & 0.589 & 0.233 & $<0.001$ & 0.570 & 0.221 & $<0.001$ \\
\hline Diameter of femoral neck (mm) & 0.754 & 0.300 & $<0.001$ & 0.791 & 0.313 & $<0.001$ & 0.783 & 0.304 & $<\mathbf{0 . 0 0 1}$ \\
\hline
\end{tabular}

Significant results are in bold $(p$ value $<0.05$ ). All models included a treatment dummy variable (group: football, swimming, cycling and control)

$\beta$ standardised regression coefficient, Semip corr semi-partial (part) correlation, $a B M D$ areal bone mineral density

${ }^{a}$ Model 1 In additional to DXA derived lean mass (total body less head, kilograms), the following independent variables were entered into the model: height (centimeters) and age (years)

${ }^{\mathrm{b}}$ Model 2 model $1+$ moderate-to-vigorous physical activity (minutes per day)

${ }^{\mathrm{c}}$ Model 3 model $2+$ DXA derived fat mass (total body less head, kilograms) 
bone variables was eliminated. These findings were consistent when substituting BMC as the dependent variable. Finally, objectively measured MVPA did not appear to play an important confounding role within the association of either LM or FM with bone health.

The strong relationship between LM and indices of bone strength and structure in the current study is supported by the mechanostat theory, which suggests that the skeleton continually adapts its strength to the loads to which it is exposed (Schoenau and Frost 2002; Rauch et al. 2004). Since the largest physiological load comes from muscle contraction, the theory postulates that increasing muscle mass (and thus muscle force) during childhood and adolescent growth will increase the mass and strength of bone (Schoenau and Frost 2002; Rauch et al. 2004). Moreover, genetic factors are thought to influence both muscle and bone (Tanaka et al. 2014), and several factors that determine bone strength by acting directly on osteoblasts and/ or osteoclasts also affect muscle. These include growth hormone, androgens and adrenocortical steroid analogues, in addition to calcium (Schoenau and Frost 2002; Courteix et al. 2015). In the present study, self-reported dietary intake of calcium was not associated with any measure of aBMD (data not shown). While this may reflect the limitation of a single, self-reported 24-hour food recall, a lack of correlation between daily calcium intake and bone outcomes is consistent with many observational and interventional studies in this area (Lloyd et al. 2002).

There is disagreement regarding the relative importance of LM and FM for bone health, in addition to the effect of FM alone on bone outcomes during childhood and adolescence. The findings of the current study agree with previous reports demonstrating negative associations between FM and some parameters of bone health (Hong et al. 2010; Hrafnkelsson et al. 2010; Savers and Tobias 2010), as well as those suggesting that bone strength is primarily related to dynamic loads associated with muscle contractions rather than to static loads associated with body weight (Pietrobelli et al. 2002; Janicka et al. 2007). In a cohort of male adolescents and young adults, Janicka and colleagues demonstrated either weak positive or nonsignificant relations between FM and bone measures using simple linear regressions (Janicka et al. 2007). However, after adjusting for LM, FM had either a negative association or no association with CT and DXA bone parameters. Comparably, Gracia-Marco et al. (2012) established positive associations between FM and BMC of the whole body and femoral neck in adolescent boys. However, following the inclusion of LM as a covariate, the associations of FM with both BMC and aBMD at several sites were inverted. It should be noted that the relationship between FM and bone might be different due to the different effects of fat depots on bone microarchitecture as previously observed in young oligo-amenorrheic female athletes (Singhal et al. 2015). Analogous to our results, both Janicka and GraciaMarco determined strong and positive associations of LM and bone outcomes after adjusting for other confounders (Gracia-Marco et al. 2012; Janicka et al. 2007). The findings of these authors suggest that while adolescents with higher FM may have greater bone properties, this association can be fully explained by their greater amount of LM (Gracia-Marco et al. 2012). On the other hand, Pietrobelli and colleagues suggested that BMC was positively associated with both FM and LM, even after controlling for each other, as well as for age and sex (Pietrobelli et al. 2002). Nonetheless, BMC was found to have a stronger association with LM than FM. Interestingly, femoral neck aBMD was the only variable in which we did not find an association with LM. However, the rest of the hip geometry estimates showed significant associations.

A novel feature of our study is the inclusion of DXAderived HSA to reflect the geometrical and mechanical properties of bone. This provides clinically important information regarding the strength of bones that may not be captured by the more traditional measure of either aBMD or BMC. Our findings are supported by previous work. El Hage et al. (2011) found LM to be the strongest predictor of cross sectional area, cross sectional moment of inertia, section modulus and cortical thickness in adolescent boys. They also reported LM being a stronger predictor of both cross sectional area and section modulus than FM. Petit and colleagues reported that LM was significantly associated with section modulus at the femoral shaft and narrow neck, and once LM was accounted for, section modulus was equivalent in overweight and healthy weight young subjects (Petit et al. 2005). They too reported that FM was not associated with bone geometry outcomes, a finding consistent with our results after adjustment for age, height, MVPA and LM.

Previous findings in pre pubertal children indicated that FM is associated with increased bone size but negatively associated with volumetric bone density (Cole et al. 2012). These findings were independent of LM and may explain the effect of increased mechanical loading from excess body mass on bone formation. The findings of the present study provide similar evidence in active adolescents that FM is not related to bone density and strength. In addition, the results of multiple linear regression analysis indicate no significant change in indices of either aBMD or hip geometry estimates with increasing FM, for a given LM. This suggests that two physically active boys with equal LM but differing FM have similar bone properties.

The present study has several strengths. A unique inclusion compared to many studies is the evaluation of hip geometry estimates in addition to traditional bone mineral outcomes. HSA provides insight into the 
geometrical and mechanical properties of bone whilst avoiding the considerably higher radiation exposure that QCT would require. Another strength of this study is the adjustment for key confounders in the regression analyses, including height, chronological age, MVPA, FM and LM. Dietary intake of calcium was considered for entry into the regression models, but were found to have no associations with aBMD or hip geometry estimates. MPVA was measured objectively using accelerometers thus eliminating the potential errors of subjective recall. Conversely, while bone properties reflect both past and present physical activity, measuring MVPA using accelerometers does not provide information regarding past activity.

Some limitations of this study deserve comment. The cross-sectional design of the study does not enable conclusions to be drawn about a causal relationship between body composition and bone health. Confirmation of these results using a longitudinal analysis of data from the PRO-BONE study will be a future endeavour. As with all DXA-based studies, the two-dimensional nature of DXA is a limitation when examining the three-dimensional structure of bone, particularly during growth. Finally, the HSA algorithm assumes that bones are fully mineralised, which may not be the case for the participants in the current study. Additional studies using QCT may address this limitation.

\section{Conclusion}

The results of this study show a greater association of LM with aBMD and hip geometry estimates than FM in active boys, irrespective of height, chronological age and MVPA. Thus, the focus concerning bone health during childhood and adolescence should move away from adiposity or total body weight, and rather place a greater emphasis on physical activity participation and subsequent lean body mass accrual during this time.

\begin{abstract}
Acknowledgements We appreciate the participation of the adolescent and families who participated in the study and we would like to thank all the sports clubs, schools, coaches and teachers who support this study. The authors also gratefully acknowledge the CHERC researchers for their continuous support and help when needed. Ethics approval received from the following committees: (1) the Ethics Review Sector of Directorate-General of Research (European Commission, ref. number 618496); (2) the Sport and Health Sciences Ethics Committee (University of Exeter, ref. number 2014/766) and (3) the National Research Ethics Service Committee (NRES Committee South West—Cornwall \& Plymouth, ref. number 14/SW/0060).
\end{abstract}

Author contributions DV and KW obtained and analysed the data and drafted the manuscript under the supervision of LGM (principal investigator) and PK, ARB and CAW. EUG, ACM and LAM reviewed the draft. All authors have read and approved this work.

\section{Compliance with ethical standards}

Data availability statement All relevant data are within the paper.

Conflict of interest The authors have declared that no competing interests exist.

Funding The research leading to these results has received funding from the European Union Seventh Framework Programme ([FP7/20072013] under grant agreement no. PCIG13-GA-2013-618496.

Open Access This article is distributed under the terms of the Creative Commons Attribution 4.0 International License (http:// creativecommons.org/licenses/by/4.0/), which permits unrestricted use, distribution, and reproduction in any medium, provided you give appropriate credit to the original author(s) and the source, provide a link to the Creative Commons license, and indicate if changes were made.

\section{References}

Bachrach LK, Hastie T, Wang MC, Narasimhan B, Marcus R (1999) Bone mineral acquisition in healthy Asian, Hispanic, black, and Caucasian youth: a longitudinal study. J Clin Endocrinol Metab 84(12):4702-4712. doi:10.1210/jcem.84.12.6182 (PubMed PMID: 10599739)

Bailey DA, Faulkner RA, McKay HA (1996) Growth, physical activity, and bone mineral acquisition. Exerc Sport Sci Rev 24:233266 (PubMed PMID: 8744252)

Beck TJ, Ruff CB, Warden KE, Scott WW Jr, Rao GU (1990) Predicting femoral neck strength from bone mineral data. A structural approach. Invest Radiol 25(1):6-18. doi:10.1097/00004424199001000-00004. (PubMed PMID: 2298552)

Bielemann RM, Martinez-Mesa J, Gigante DP (2013) Physical activity during life course and bone mass: a systematic review of methods and findings from cohort studies with young adults. BMC Musculoskel Dis. doi:10.1186/1471-2474-14-77. (PubMed PMID: WOS:000316249100001)

Cardadeiro G, Baptista F, Rosati N, Zymbal V, Janz KF, Sardinha LB (2014) Influence of physical activity and skeleton geometry on bone mass at the proximal femur in 10- to 12-year-old children-a longitudinal study. Osteoporos Int 25(8):2035-2045. doi:10.1007/s00198-014-2729-y (PubMed PMID: 24809809)

Cole ZA, Harvey NC, Kim M, Ntani G, Robinson SM, Inskip HM, Godfrey KM, Cooper C, Dennison EM, SWsSS G (2012) Increased fat mass is associated with increased bone size but reduced volumetric density in pre pubertal children. Bone 50(2):562-567. doi:10.1016/j.bone.2011.05.005 (PubMed PMID: PMC3678245)

Courteix D, Valente-dos-Santos J, Ferry B, Lac G, Lesourd B, Chapier R et al (2015) Multilevel approach of a 1-year program of dietary and exercise interventions on bone mineral content and density in metabolic syndrome-the RESOLVE Randomized Controlled Trial. PLoS One 10(9):e0136491. doi:10.1371/journal.pone.0136491 (PubMed PMID: 26376093; PubMed Central PMCID: PMCPMC4574281)

Crabtree NJ, Arabi A, Bachrach LK, Fewtrell M, El-Hajj Fuleihan G, Kecskemethy HH, Jaworski M, Gordon CM, International Society for Clinical D (2014) Dual-energy X-ray absorptiometry interpretation and reporting in children and adolescents: the revised 2013 ISCD Pediatric Official Positions. J Clin 
Densitom 17(2):225-242. doi:10.1016/j.jocd.2014.01.003 (PubMed PMID: 24690232)

Daly RM, Stenevi-Lundgren S, Linden C, Karlsson MK (2008) Muscle determinants of bone mass, geometry and strength in prepubertal girls. Med Sci Sports Exerc 40(6):1135-1141. doi:10.1249/MSS.0b013e318169bb8d

Duke PM, Litt IF, Gross RT (1980) Adolescents' self-assessment of sexual maturation. Pediatrics 66(6):918-920 (PubMed PMID: 7454482)

Edwards MH, Ward KA, Ntani G, Parsons C, Thompson J, Sayer AA, Dennison EM, Cooper C (2015) Lean mass and fat mass have differing associations with bone microarchitecture assessed by high resolution peripheral quantitative computed tomography in men and women from the Hertfordshire Cohort Study. Bone 81:145-151. doi:10.1016/j.bone.2015.07.013

El Hage RP, Courteix D, Benhamou CL, Jacob C, Jaffre C (2009) Relative importance of lean and fat mass on bone mineral density in a group of adolescent girls and boys. Eur J Appl Physiol 105(5):759-764. doi:10.1007/s00421-008-0959-4 (PubMed PMID: 19096868)

El Hage Z, Theunynck D, Jacob C, Moussa E, Baddoura R, Kamle $P$ et al (2011) Hip bone strength indices in overweight and control adolescent boys. J Bone Miner Metab 29(6):691-698. doi:10.1007/s00774-011-0267-7 (PubMed PMID: 21626089)

Farr JN, Amin S, LeBrasseur NK, Atkinson EJ, Achenbach SJ, McCready LK et al (2014) Body composition during childhood and adolescence: relations to bone strength and microstructure. J Clin Endocrinol Metab 99(12):4641-4648. doi:10.1210/ jc.2014-1113 (PubMed PMID: 25243571; PubMed Central PMCID: PMCPMC4255129)

Gracia-Marco L (2016) Physical activity, bone mass and muscle strength in children. Acta Paediatr 105(10):1127-1128. doi:10.1111/apa.13511 (PubMed PMID: 27634683)

Gracia-Marco L, Ortega FB, Jimenez-Pavon D, Rodriguez G, Castillo MJ, Vicente-Rodriguez G, et al. (2012) Adiposity and bone health in Spanish adolescents. The HELENA study. Osteoporos Int 23(3):937-947. doi:10.1007/s00198-011-16493. (Epub 2011/05/13, PubMed PMID: 21562873)

Hong XM, Arguelles LM, Liu X, Tsai HJ, Hsu YH, Wang BY et al (2010) Percent fat mass is inversely associated with bone mass and hip geometry in rural Chinese adolescents. J Bone Miner Res 25(7):1544-1554. doi:10.1002/jbmr.40 (PubMed PMID: WOS:000280395900010)

Hoy CL, Macdonald HM, McKay HA (2013) How does bone quality differ between healthy-weight and overweight adolescents and young adults? Clin Orthop Relat R 471(4):12141225. doi:10.1007/s11999-012-2576-0 (PubMed PMID: WOS:000315510400025)

Hrafnkelsson H, Sigrudsson G, Magnusson KT, Johannsson E, Sigurdsson EL (2010) Factors associated with bone mineral density and content in 7-year-old children. Bone 46(4):10581062. doi:10.1016/j.bone.2009.11.035 (PubMed PMID: WOS:000276009400027)

Hrafnkelsson H, Sigurdsson G, Magnusson KT, Sigurdsson EL, Johannsson E (2013) Fat mass increase in 7-year-old children: more bone area but lower bone mineral density. J Bone Miner Metab 31(4):442-448. doi:10.1007/s00774-013-0423-3 (PubMed PMID: 23397377)

Jackowski SA, Lanovaz JL, Van Oort C, Baxter-Jones AD (2014) Does lean tissue mass accrual during adolescence influence bone structural strength at the proximal femur in young adulthood? Osteoporos Int 25(4):1297-1304. doi:10.1007/s00198013-2592-2 (PubMed PMID: 24326885)

Janicka A, Wren TAL, Sanchez MM, Dorey F, Kim PS, Mittelman SD et al (2007) Fat mass is not beneficial to bone in adolescents and young adults. J Clin Endocr Metab
92(1):143-147. doi:10.1210/jc.2006-0794 (PubMed PMID: WOS:000243317500027)

Janz KF, Letuchy EM, Burns TL, Eichenberger Gilmore JM, Torner JC, Levy SM (2014) Objectively measured physical activity trajectories predict adolescent bone strength: Iowa Bone Development Study. Br J Sports Med 48(13):1032-1036. doi:10.1136/bjsports-2014-093574

Jeddi M, Dabbaghmanesh MH, Ranjbar Omrani G, Ayatollahi SM, Bagheri Z, Bakhshayeshkaram M (2015) Relative importance of lean and fat mass on bone mineral density in iranian children and adolescents. Int $\mathbf{J}$ Endocrinol Metab 13(3):e25542. doi:10.5812/ijem.25542v2 (PubMed PMID: PMC4577805)

Joeris A, Lutz N, Wicki B, Slongo T, Audige L (2014) An epidemiological evaluation of pediatric long bone fractures - a retrospective cohort study of 2716 patients from two Swiss tertiary pediatric hospitals. BMC Pediatr 14:314. doi:10.1186/s12887014-0314-3 (PubMed PMID: 25528249)

Johnson J, Dawson-Hughes B (1991) Precision and stability of dual-energy X-ray absorptiometry measurements. Calcif Tissue Int 49(3): 174-178

Khoo BC, Beck TJ, Qiao QH, Parakh P, Semanick L, Prince RL, Singer KP, Price RI (2005) In vivo short-term precision of hip structure analysis variables in comparison with bone mineral density using paired dual-energy X-ray absorptiometry scans from multi-center clinical trials. Bone 37(1):112-121. doi:10.1016/j.bone.2005.03.007

Lappe JM, Watson P, Gilsanz V, Hangartner T, Kalkwarf HJ, Oberfield S, Shepherd J, Winer KK, Zemel B (2014) The longitudinal effects of physical activity and dietary calcium on bone mass accrual across stages of pubertal development. J Bone Miner Res. doi:10.1002/jbmr.2319 (PubMed PMID: PMC4280289)

Lima F, De Falco V, Baima J, Carazzato JG, Pereira RM (2001) Effect of impact load and active load on bone metabolism and body composition of adolescent athletes. Med Sci Sports Exerc 33(8):1318-1323 (PubMed PMID: 11474333)

Lloyd T, Beck TJ, Lin HM, Tulchinsky M, Eggli DF, Oreskovic TL et al (2002) Modifiable determinants of bone status in young women. Bone 30(2):416-421 (PubMed PMID: 11856651)

Martin RB, Burr DB (1984) Non-invasive measurement of long bone cross-sectional moment of inertia by photon absorptiometry. J Biomech 17(3):195-201 (PubMed PMID: 6736056)

Morris NM, Udry JR (1980) Validation of a self-administered instrument to assess stage of adolescent development. J Youth Adolesc 9(3):271-280. doi:10.1007/bf02088471

Mosca LN, Goldberg TB, da Silva VN, da Silva CC, Kurokawa CS, Bisi Rizzo AC, Corrente JE (2014) Excess body fat negatively affects bone mass in adolescents. Nutrition 30(7-8):847-852. doi:10.1016/j.nut.2013.12.003 (PubMed PMID: 24985003)

Petit MA, Beck TJ, Shults J, Zemel BS, Foster BJ, Leonard MB (2005) Proximal femur bone geometry is appropriately adapted to lean mass in overweight children and adolescents. Bone 36(3):568-576. doi:10.1016/j.bone.2004.12.003 (PubMed PMID: WOS:000228196900022)

Phillips LR, Parfitt G, Rowlands AV (2013) Calibration of the GENEA accelerometer for assessment of physical activity intensity in children. J Sci Med Sport 16(2):124-128. doi:10.1016/j. jsams.2012.05.013 (PubMed PMID: 22770768)

Pietrobelli A, Faith MS, Wang J, Brambilla P, Chiumello G, Heymsfield SB (2002) Association of lean tissue and fat mass with bone mineral content in children and adolescents. Obes Res 10(1):5660. doi:10.1038/oby.2002.8 (PubMed PMID: 11786602)

Prevrhal S, Shepherd JA, Faulkner KG, Gaither KW, Black DM, Lang TF (2008) Comparison of DXA hip structural analysis with volumetric QCT. J Clin Densitom 11(2):232-236. doi:10.1016/j. jocd.2007.12.001 (PubMed PMID: 18280192) 
Rauch F, Bailey DA, Baxter-Jones A, Mirwald R, Faulkner R (2004) The 'muscle-bone unit' during the pubertal growth spurt. Bone 34(5):771-775. doi:10.1016/j.bone.2004.01.022 (PubMed PMID: WOS:000221461700002)

Reid IR (2008) Relationships between fat and bone. Osteoporosis Int 19(5):595-606. doi:10.1007/s00198-007-0492-z (PubMed PMID: WOS:000254625200001)

Rich C, Geraci M, Griffiths L, Sera F, Dezateux C, Cortina-Borja M (2013) Quality control methods in accelerometer data processing: defining minimum wear time. PLoS One 8(6):e67206. doi:10.1371/journal.pone.0067206 (PubMed PMID: 23826236; PubMed Central PMCID: PMC3691227)

Rizzoli R, Bianchi ML, Garabedian M, McKay HA, Moreno LA (2010) Maximizing bone mineral mass gain during growth for the prevention of fractures in the adolescents and the elderly. Bone 46(2):294-305. doi:10.1016/j.bone.2009.10.005. (Epub 2009/10/21, PubMed PMID: 19840876)

Sayers A, Tobias JH (2010) Fat mass exerts a greater effect on cortical bone mass in girls than boys. J Clin Endocrinol Metab 95(2):699-706. doi: 10.1210/jc.2009-1907(PubMed PMID: 20008022; PubMed Central PMCID: PMCPMC2817095)

Schoenau E (2005) From mechanostat theory to development of the "Functional Muscle-Bone-Unit". J Musculoskelet Neuronal Interact 5(3):232-238 (PubMed PMID: 16172514)

Schoenau E, Frost HM (2002) The "muscle-bone unit" in children and adolescents. Calcified Tissue Int 70(5):405-407. doi:10.1007/ s00223-001-0048-8 (PubMed PMID: WOS:000176111300007)

Scott A, Khan KM, Duronio V, Hart DA (2008) Mechanotransduction in human bone in vitro cellular physiology that underpins bone changes with exercise. Sports Med 38(2):139-160. doi:10.2165/00007256-200838020-00004 (PubMed PMID: 18201116)

Singhal V, Maffazioli GD, Cano Sokoloff N, Ackerman KE, Lee H, Gupta N, Clarke H, Slattery M, Bredella MA, Misra M (2015) Regional fat depots and their relationship to bone density and microarchitecture in young oligo-amenorrheic athletes. Bone 77:83-90. doi:10.1016/j.bone.2015.04.005

Streeter AJ, Hosking J, Metcalf BS, Jeffery AN, Voss LD, Wilkin TJ (2013) Body fat in children does not adversely influence bone development: a 7-year longitudinal study (EarlyBird 18). Pediatr Obes 8(6):418-427. doi:10.1111/j.2047-6310.2012.00126.x (PubMed PMID: 23447431)

Tanaka K, Kanazawa I, Yamaguchi T, Yano S, Kaji H, Sugimoto T (2014) Active vitamin D possesses beneficial effects on the interaction between muscle and bone. Biochem Biophys Res Co 450(1):482-487. doi:10.1016/j.bbrc.2014.05.145 (PubMed PMID: WOS:000343641000079)

Torres-Costoso A, Gracia-Marco L, Sanchez-Lopez M, NotarioPacheco B, Arias-Palencia N, Martinez-Vizcaino V (2015) Physical activity and bone health in schoolchildren: the mediating role of fitness and body fat. PLoS One 10(4):e0123797. doi:10.1371/journal.pone.0123797 (PubMed PMID: 25915941; PubMed Central PMCID: PMC4411135)

Vlachopoulos D, Barker AR, Williams CA, Knapp KM, Metcalf BS, Gracia-Marco L (2015) Effect of a program of short bouts of exercise on bone health in adolescents involved in different sports: the PRO-BONE study protocol. BMC Public Health 15(1):361. doi:10.1186/s12889-015-1633-5

Vlachopoulos D, Ubago-Guisado E, Barker AR, Metcalf BS, Fatouros IG, Avloniti A, Knapp KM, Moreno LA, Williams CA, GraciaMarco L (2017) Determinants of bone outcomes in adolescent athletes at baseline: the PRO-BONE study. Med Sci Sports Exerc. doi:10.1249/MSS.0000000000001233

Wang QJ, Cheng SL, Alen M, Seeman E, Grp FCS (2009) Bone's structural diversity in adult females is established before puberty. J Clin Endocrinol Metab 94(5):1555-1561. doi:10.1210/ jc.2008-2339

Weber JL, Lytle L, Gittelsohn J, Cunningham-Sabo L, Heller K, Anliker JA, Stevens J, Hurley J, Ring K (2004) Validity of selfreported dietary intake at school meals by American Indian children: the Pathways Study. J Am Diet Assoc 104(5):746-752. doi:10.1016/j.jada.2004.02.029

Weeks BK, Beck BR (2012) Are bone and muscle changes from POWER PE, an 8-month in-school jumping intervention, maintained at three years? PLoS One 7(6):e39133. doi:10.1371/journal.pone.0039133 